\title{
LA ESCLAVITUD EN LA ESPAÑA BAJOMEDIEVAL (SIGLOS XIV-XV). GENERALIDADES Y RASGOS DIFERENCIALES
}

\section{SLAVERY IN LATE MEDIEVAL SPAIN (14TH-15TH CENTURIES). GENERALITIES AND DIFFERENTIAL FEATURES}

Raúl González Arévalo

Universidad de Granada

\section{RESUMEN}

El presente artículo aborda desde una perspectiva general e integradora el conocimiento de la esclavitud en los territorios de lo que hoy es España en época bajomedieval, centrado en las Coronas de Aragón y Castilla en los siglos XIV y XV. Se estudia la imagen mediática de la esclavitud; la procedencia de las personas esclavizadas y su distribución ibérica; la imagen del esclavo, su trabajo, su vida y su posición en la sociedad; los propietarios, las dificultades para alcanzar la libertad y el estigma de los libertos.

Palabras clave: Resclavitud, España medieval, comercio, trabajo, vida, sociedad.

\section{ABSTRACT}

The present paper tackles from a general and integrating perspective the knowledge of slavery in the late medieval territories that today shape Spain, focusing in the Crowns of Aragon and Castile in the 14th and 15th centuries. It deals with media image of slavery; the origin of enslaved people and their Iberian distribution, the slave's image, labour, life and social position; owners, the difficulties to reach liberty and freed slaves' stigma.

Keywords: slavery, Medieval Spain, trade, labour, life, and society. 


\section{RESUM \\ L'ESCLAVITUD A L'ESPANYA MEDIEVAL (SEGLES XIV-XV). GENERA- LITATS I TRETS DIFERENCIALS}

El present article tracta des d'una perspectiva general i integradora el coneixement de l'esclavitud als territoris del que avui dia és Espanya en la baixa edat mitjana, centrat a les Corones d'Aragó i Castella en els segles XIV i XV. S'estudia la imatge mediàtica de l'esclavitud; la procedència de les persones esclavitzades i la seua distribució ibèrica; la imatge de l'esclau, el seu treball, la seua vida i posició en la societat; els propietaris, les dificultats per aconseguir la llibertat i l'estigma dels lliberts.

Paraules clau: Resclavitud, Espanya medieval, comerç, treball, vida, societat. 


\section{Del cine a la esclavitud medieval}

Cuando hablamos de esclavitud hoy día las imágenes e ideas que todos tenemos en la cabeza de modo inconsciente nos llevan inmediatamente a la Antigüedad y las colonias americanas. El cine es responsable en buena medida de esta circunstancia, pues la imagen del esclavo es fácilmente reconocible en la Roma imperial, con esclavos y gladiadores en películas como Espartaco o Gladiator. De la misma manera, se ha difundido la imagen de la trata negrera que entre los siglos XVI y XIX arrancó 11 millones de personas de sus casas en el África subsahariana para llevarlas contra su voluntad a América, según han estimado las investigaciones promovidas desde la UNESCO a través de su programa The Slave Route, cuyo objetivo declarado era dar a conocer la tragedia y devolver la dignidad a los seres humanos que sufrieron esta tragedia, saliendo del rincón del olvido de la Historia. ' Las huellas de esta migración forzosa son visibles en la población mulata de Sudamérica, especialmente en Brasil y el Caribe, en islas como Cuba, donde la esclavitud fue particularmente fuerte. En Estados Unidos la conciencia de la esclavitud es mayor aún y la población afroamericana la recuerda para reivindicar igualdad en materia de derechos civiles y sociales. Hollywood lo ha plasmado puntualmente, pasando de la imagen amable de la esclavitud doméstica y agrícola de Lo que el viento se llevó, con el primer Óscar como actriz secundaria para una intérprete negra

1 Un buen resumen en THOMAS, Hugh (2001), La trata de esclavos. Historia del tráfico de seres humanos de 1440 a 1870, Planeta, Madrid. 
(Hattie McDaniel) en 1939, a la imagen más dura y realista de 12 años en esclavitud, Óscar a la mejor película en $2014 .^{2}$

Lo cierto es que la esclavitud es uno de los fenómenos más antiguos de la Humanidad. No hay prácticamente civilización desde la Antigüedad hasta la época contemporánea que no la haya conocido. ${ }^{3}$ Durante la Alta Edad Media convivieron un gran número de formas de dependencia, incluida la esclavitud, si bien es cierto que como tal prácticamente había desaparecido en Europa occidental, salvo en zonas muy puntuales, en la península ibérica, Italia y el sur de Francia. ${ }^{4}$ Precisamente por una parte la lucha con el Islam provocó un flujo importante de esclavos desde los reinos cristianos hacia al-Andalus, y por otra llegaban las rutas caravaneras con esclavos subsaharianos. En sentido inverso, conforme avanzó la conquista cristiana sobre el Islam andalusí aumentó el volumen de musulmanes privados de libertad en el norte peninsular. ${ }^{5}$ Con todo, cabe precisar que muchos de ellos eran cautivos, no esclavos. Aunque hay una tendencia actual a asimilar los dos fenómenos por las coincidencias en la privación de libertad de las personas y su explotación laboral, lo cierto es que en realidad se trataba de dos situaciones jurídicamente bien diferenciadas, en el Islam como en la Cristiandad, en la que lejos de ser dos caras de una misma realidad, lo cierto es que el cautiverio es un estadio jurídicamente anterior, que no conducía necesariamente a la esclavitud, y que tenía sus propios mecanismos. ${ }^{6}$

2 Para un estudio sobre el cine como el principal medio difusor de la historia de la esclavitud véase Z. DAVIS, Natalie, (2002), Slaves on Screen. Film and Historical Vision, Harvard University Press, Cambridge (MA); y MARTIN, Michael T., y WALL, David C. (2013), "The Politics of Cine-Memory: Signifying Slavery in the History Film", en ROSENSTONE, Robert A. y PARVULESU, Constantin (eds.), A Companion to the Historical Film, Wiley-Blackwell, Oxford, pp. 445-467.

3 Para un recorrido de la historia de la esclavitud desde la Prehistoria hasta nuestros días puede verse MELTZER, Milton (1993), Slavery. A World History, Da Capo Press, Nueva York.

4 No se ha repetido el esfuerzo integrador de la obra clásica de VERLINDEN, Charles (1955), L'esclavage dans l'Europe médiévale. Tome I: Péninsule Ibérique, France, De Tempel, Brujas; y (1977), L'esclavege dans l'Europe médiévale. Tome II: Italie - Colonies italiennes du Levant Levant latin - Empire byzantin, Rijksuniversiteit, Gante. Una puesta al día sobre la servidumbre y la esclavitud en Europa en CAVACIOCCHI, Simonetta (ed.) (2014), Schiavitù e servaggio nell'economia europea, secc. XI-XVIII, Firenze University Press, Florencia.

5 A falta de un volumen específico sobre la esclavitud en al-Andalus me remito a los estudios contenidos en FIERRO, Maribel y GARCÍA-FITZ, Francisco (eds.) (2008), El cuerpo derrotado: cómo trataban musulmanes y cristianos a los enemigos vencidos (Península lbérica, ss. VIII-XIII), CSIC, Madrid. 
La esclavitud bajomedieval es fruto del renacimiento de la trata en los inicios del siglo XIII, no de la evolución de las situaciones de dependencia conocidas en la Europa de la Alta y la Plena Edad Media. Impulsada por las repúblicas mercantiles italianas, Génova y Venecia, que contaban con importantes colonias en el Levante mediterráneo y Próximo Oriente, empezaron a exportar esclavos eslavos al sultanato mameluco de Egipto y hacia el Mediterráneo occidental. A diferencia de la esclavitud antigua y moderna, eminentemente rurales, la esclavitud europea fue un fenómeno esencialmente urbano, circunscrito al ámbito del Mediterráneo. ${ }^{7}$ En consecuencia, por lo que respecta a la península ibérica, se desarrolló antes en la Corona de Aragón que en la de Castilla donde, por el contrario, seguía teniendo más peso el botín obtenido con la "guerra del moro", las luchas seculares con los musulmanes de al-Andalus, en la que el cautivo enemigo era el botín más preciado. De hecho, Castilla no se incorporó con fuerza a los circuitos esclavistas mediterráneos hasta después de la conquista del Reino de Granada a finales del siglo XV, ya durante el reinado de los Reyes Católicos. De la misma manera, tampoco Portugal tuvo una participación relevante en esta esclavitud mediterránea.

Los historiadores de la esclavitud europea hacen enorme hincapié no sólo en la aceptación que tenía entre la población el hecho esclavo, con un discurso jurídico, ideológico y teológico que lo justificaba, articulado en torno a los escritos de autores de la Antigüedad (encabezados por Aristóteles) y la Edad Media, incluyendo San Agustín y Santo Tomás de Aquino. Efectivamente, los argumentos a favor de la esclavitud son muchos y variados, y constituyeron un corpus coherente, aunque no homogéneo. ${ }^{8}$

6 Para las diferencias entre cautiverio y esclavitud en la Baja Edad Media ibérica me remito a GONZÁlEZ ARÉVALO, Raúl (2006), El cautiverio en Málaga a fines de la Edad Media, CEDMA, Málaga, pp. 23-36. Para los cautivos cristianos y musulmanes en la Península lbérica véase el magnífico volumen de CALDERÓN ORTEGA, José Manuel y DÍAZ GONZÁLEZ, Francisco Javier (col.) (2012), Vae Victis. Cautivos y prisioneros en la Edad Media Hispánica, Universidad de Alcalá de Henares, Madrid.

7 HEERS, Jacques (1989), Esclavos y sirvientes en las sociedades mediterráneas durante la Edad Media, Institución Alfonso el Magnánimo, Valencia. Una puesta al día reciente, referida al cautiverio y la esclavitud, en los estudios contenidos en GUILLEN, Fabienne y TRABELSI, Salah (eds.) (2012), Les esclavages en Méditerranée. Espaces et dynamiques économiques, Casa de Velázquez, Madrid.

8 GARCÍA AÑOVEROS, Jesús (2000), El pensamiento y los argumentos sobre la esclavitud en Europa en el siglo XVI y su aplicación a los indios americanos y a los negros africanos, CSIC, Madrid. 


\section{Geografía Y procedencia de la esclavitud ibérica}

La situación de la península ibérica entre el Mediterráneo y el Atlántico hace que se puedan distinguir dos áreas en las que los mecanismos de aprovisionamiento de personas esclavizadas estaban diferenciados. Efectivamente, la Corona de Aragón se integró rápidamente en los circuitos esclavistas mediterráneos que la abastecieron de individuos de procedencia oriental y de musulmanes, mientras que en Castilla tuvo más importancia el desarrollo de la trata negrera africana en cuyo impulso Portugal tuvo un papel decisivo desde mediados del siglo XV. Pero ambos territorios compartían una característica: la presencia más abundante en las ciudades cercanas a la costa y más débil en el interior. De hecho, en el sur peninsular se puede trazar una frontera invisible entre el sur del río Guadiana, con la Extremadura meridional y Andalucía como territorios de mayor presencia esclava, y el interior, donde apenas está constatada. Por su parte, en la Corona de Aragón destacan la costa catalana y valenciana, así como el Reino de Mallorca. Así lo han confirmado los estudios específicos sobre la materia, que han determinado que los grandes centros esclavistas peninsulares eran Lisboa y Sevilla para la trata atlántica; ${ }^{9}$ Málaga en el Reino de Granada después de la conquista castellana, a caballo entre el Mediterráneo y el Atlántico; ${ }^{10}$ y Barcelona, Valencia y Palma de Mallorca en el Mediterráneo ibérico. ${ }^{11}$

Inicialmente la presencia de la esclavitud mediterránea en la Corona de Aragón se centró en la capital catalana, Barcelona, el centro indiscutible

9 FRANCO SILVA, Alfonso (1979), La esclavitud en Sevilla y su tierra a fines de la Edad Media, Diputación Provincial de Sevilla, Sevilla.

10 GONZÁlEZ ARÉVALO, Raúl (2006), La esclavitud en Málaga a fines de la Edad Media, Universidad de Jaén, Jaén.

11 CORTÉS, Vicenta (1964), La esclavitud en Valencia durante el reinado de los Reyes Católicos, Ayuntamiento de Valencia, Valencia; VAQUER BENNASSAR, Onofre (1997), L'esclavitud a Mallorca, 1448-1500, Consell Insular de Mallorca, Palma de Mallorca; SALICRÚ, Roser (1998), Esclaus i propietaris d'esclaus a la Catalunya del segle XV. L'assegurança contra fugues, CSIC, Barcelona; HERNANDO, Josep (2003), Els esclaus islàmics a Barcelona: blancs, negres, llors i turcs. De l'esclavitud a la llibertat (s. XIV), CSIC, Barcelona. MARZAL, Francisco Javier (2006), La esclavitud en Valencia durante la Baja Edad Media (1375-1425), Universitat de València, Valencia; BLUMENTHAL, Debra (2009), Enemies and Familiars: Slavery and Mastery in Fifteenth-Century Valencia, Cornell University Press, Ithaca; ARMENTEROS, Iván (2015), L'esclavitud a la Barcelona del Renaixement (1479-1516). Un port mediterrani sota la influència del primer tràfic negrer, Fundació Noguera, Barcelona; FERRER ABÁRZUZA, Antoni (2015), Captius i senyors de captius a Eivissa. Una contribució al debat sobre l'esclavitud 
en Cataluña. En el siglo XIV los catalanes se abastecían en el Mar Egeo de esclavos orientales (tártaros, rusos circasianos, abjasios, mingrelianos). En el Mediterráneo central había relaciones fuertes de aprovisionamiento con Génova y Sicilia, donde adquieren esclavos de procedencia muy diversa, desde sarracenos norteafricanos hasta eslavos de los Balcanes (albaneses, bosnios, búlgaros, esclavones y griegos). Con todo, el avance del Imperio otomano en el Mediterráneo oriental y el cambio de las dinámicas comerciales hicieron que a finales del siglo XV la esclavitud oriental y balcánica fuera residual, frente al auge de magrebíes $y$, más adelante, de subsaharianos, cuando el impacto de la trata atlántica cambió para siempre el mercado barcelonés. ${ }^{12}$

Mallorca también fue un importantísimo centro esclavista desde su conquista en el siglo XIII, y los estudios demuestran que, al menos al principio, la actividad agrícola estaba en manos de esclavos musulmanes, que progresivamente fueron sustituidos por campesinos libres asalariados ante el temor, entre otras cosas, de una rebelión en la isla, pues al principio había más esclavos que libres. ${ }^{13}$

Con todo, el gran centro esclavista a partir del siglo XV en la Corona de Aragón fue Valencia, que compitió con Barcelona como centro comercial y financiero más dinámico. El volumen de cifras es impresionante, sólo por detrás de Lisboa en todo Occidente. Se observa una evolución desde la diversidad del siglo XIV, con esclavos orientales y balcánicos como en Barcelona, pues conforme avanza el siglo XV la presencia de grandes mercaderes de esclavos desemboca en un flujo constante, cada vez mayor, de individuos privados de libertad procedentes del África negra, llevados por los portugueses; de canarios, esclavizados por castellanos; y de moros,

medieval (segles XIII-XVI), Universitat de València, Valencia. Además, en el siguiente volumen colectivo la mayoría de las contribuciones se refieren al ámbito de la Corona de Aragón: FERRER, María Teresa y MUTGÉ, Josefina (eds.) (2000), De l'esclavitud a la llibertat: Esclaus i lliberts a l'edat mitjana, CSIC, Barcelona.

12 Como resulta evidente de la lectura de los trabajos de Josep Hernando e Iván Armenteros citados en la nota anterior.

13 SOTO, Ricardo (2012), "La conquista de Mallorca y la creación de un mercado de esclavos" y MAS FORNERS, Antoni (2012), "La incidencia del mercado de esclavos en la estructura productiva de Mallorca (c. 1300-1450)", en GUILLEN y TRABELSI, Les esclavages en Méditerranée, pp. $63-76$ y 77-100, respectivamente. 
reducidos a esclavitud por catalanes. Esto la convirtió junto con Génova y Venecia en uno de los grandes mercados de esclavos de todo el Mediterráneo occidental. ${ }^{14}$

En la Corona de Castilla mientras hubo frontera terrestre con el Islam, con el Reino de Granada, hasta finales del siglo XV, la presencia de esclavos moros fue más importante en las zonas fronterizas, Andalucía y el Reino de Murcia. La guerra del moro y la esclavitud de musulmanes fue el tipo que definió la esclavitud en Castilla en el siglo XIV y principios del XV. ${ }^{15}$

Por otra parte, en la fachada atlántica la trata negrera de origen portugués se dejó notar con mucha fuerza a partir de 1450. No era ajeno el impacto del nuevo comercio con América, pues muchos mercaderes aprovechaban la presencia de la Casa de la Contratación en Sevilla para contratar la exportación de esclavos africanos a cambio de productos del Nuevo Mundo. El papel redistribuidor de Sevilla no era nuevo: desde el siglo XV se exportaban esclavos a los demás puertos andaluces -Cádiz, Puerto de Santa María, Sanlúcar de Barrameda, cabeceras asimismo para las expediciones contra el Magreb occidental, en las que se esclavizaban árabes y berberiscos norteafricanos- pero también del Mediterráneo occidental como Valencia, Barcelona, Génova y Pisa. ${ }^{16}$

Con la conquista de Granada en 1492 el nuevo territorio incorporado se convirtió también en un gran mercado esclavista, pero con caracteres propios: la cercanía con las costas del Norte de África y las operaciones bélicas contra el Magreb hicieron que en los albores de la Modernidad en esta parte de la Península lbérica tuviera mucho más peso la población esclava de origen musulmán que en el resto de la Península.

Entre los esclavos musulmanes -también llamados blancos por el color de la piel, en contraposición a los negros, o de manera genérica "moros"encontramos árabes, beréberes y turcos. Algunos procedían del emirato nazarí (Granada y Málaga), otros de la costa mediterránea del Magreb, la 'Berbería de Levante' (Trípoli, Túnez, Bona, Orán, Tremecén, Monastir, Sfax) y por último, los menos, de la 'Berbería de Poniente', el Magreb atlántico (Arcila, Azamor). Se trata de una esclavitud ligada a empresas

14 Véanse las publicaciones de Francisco Javier Marzal y Vicenta Cortés en la nota 11.

15 MOLINA, Ángel Luis (1978), "Contribución al estudio de la esclavitud en Murcia a fines de la Edad Media (1475-1516)", Murgetana, n53, pp. $111-134$.

16 Para una visión global sobre la esclavitud en Andalucía me remito a FRANCO SILVA, Alfonso (1992), La esclavitud en Andalucía (1450-1550), Editorial Universidad de Granada, Granada. 
bélicas, que tuvieron un enorme impacto en los mercados ibéricos, como la conquista de Málaga (1487): la práctica totalidad de la población, unos 11.000 individuos, fue reducida al cautiverio por derecho de guerra y terminó siendo vendida como esclava en las ciudades andaluzas -Sevilla, Córdoba y Jerez de la Frontera- pero también en Valencia y Barcelona. ${ }^{17}$

Las otras conquistas castellanas fuera de la Península Ibérica también se dejaron sentir en los mercados hispanos. Los primeros esclavos canarios llegaron a Sevilla a finales del siglo XIV, aunque la mayor afluencia tuvo lugar con el sometimiento definitivo del archipiélago a finales del siglo XV, tras la conquista de Tenerife y la represión de la revuelta de La Gomera, cuando guanches y gomeros fueron vendidos en abundancia en el mercado hispalense y Valencia. ${ }^{18}$ Por su parte, la toma de las principales plazas norteafricanas -Orán en 1509, Bujía y Trípoli en 1510-proporcionaron abundante población esclava árabe, pero también judía.

La esclavitud negra es diferente. Desde finales del siglo XIII y durante dos siglos a los puertos de la Corona de Aragón llegaban negros de los "Montes de Barca", en la actual Libia, donde se embarcaban esclavos procedentes de África central, pertenecientes a las etnias kanem y hausa. Sin embargo, a partir de la segunda mitad del siglo XV se impuso con fuerza el nuevo eje esclavista Lisboa-Sevilla-Valencia -el más importante de Europa occidental, uniendo los principales mercados ibéricos- de la mano de los mercaderes portugueses que desde la capital lusa distribuían esclavos procedentes de África occidental. Así, detrás de la procedencia genérica de "Guinea" -localizada entre Senegambia y el Golfo de Guinea- en ocasiones es posible determinar el origen étnico de los esclavos, fundamentalmente wolofes y mandingas. ${ }^{19}$

La presencia de una población esclava de origen etnogeográfico tan diverso dio lugar a la aparición de cruces raciales que desembocaron en la acuñación de una nueva categoría, los "loros", que en realidad no eran otra cosa que esclavos mulatos, aunque, a diferencia de la América colonial, en el mundo ibérico medieval nunca fueron numerosos.

17 LADERO QUESADA, Miguel Ángel (1967), "La esclavitud por guerra a fines del siglo XV: el caso de Málaga", Hispania, n 105, pp. 63-87.

18 FRANCO SILVA, Alfonso (1988), "El esclavo canario en el mercado de Sevilla a finales de la Edad Media (1470-1525)", en VIII Coloquio de Historia Canario-Americana, Cabildo Insular de Gran Canaria, Las Palmas de Gran Canaria, tomo 1, pp. 54-66.

19 CORTÉS, Vicenta (1972), "Procedencia de los esclavos negros de Valencia (1482-1516)", Revista Española de Antropología Americana, n 7/1, pp. 123-152. 


\section{¿Hombre-ANImal? ¿esclava SeXUal? Entre el estereotipo y la Realidad}

Sobre la población esclava se han generado y perviven una serie de imágenes que oscilan entre el estereotipo y la realidad. En primer lugar cabe abordar la imagen del hombre-mercancía, directamente relacionada con la del hombre-animal, cuya generalización han reivindicado vehementemente algunos autores. Se trata de una realidad indiscutible, que emerge con fuerza de los protocolos notariales, y más concretamente de las cartas de compraventa, en las que la descripción física de la mercancía y su estado -enfermedades, heridas, señales o características particulares- han servido para señalar un proceso de animalización de la persona hasta integrarlo en el ganado humano que constituía la población esclava. Los términos para designar el color de la piel, así como el uso de los términos "pieça" - "cabeça" de esclavo también proceden de la nomenclatura animal, aúnque quienes abogan por la realidad de la imagen tópica del esclavo-animal se han centrado sobre todo en la reivindicación del uso reiterado de hierros y herrajes. ${ }^{20}$ Sin embargo, la documentación hispana revela que su empleo no era en absoluto mayoritario.

La asimilación con el mundo animal resulta especialmente evidente cuando los esclavos figuran junto al ganado en las normativas municipales. Un buen ejemplo lo ofrecen las de Gran Canaria (1531), cuyas ordenanzas prohibían a quienes no fueran vecinos llevar carretas "ni camello, ni bestias, ni esclavos" al puerto de la ciudad. Así, el individuo privado de libertad recibía claramente el tratamiento de bestia de carga. ${ }^{21}$ En Sevilla los pregoneros tenían que pregonar "esclavo, o cavallo, o mula, o otra cosa que anduviese perdida" por las principales plazas de la ciudad. ${ }^{22}$ Más aún, en las localidades rurales el esclavo podía valer incluso menos que el ganado. Es lo que vemos en Alcalá de los Gazules, en el Estrecho de Gibraltar, donde el marqués de Tarifa ordenaba que a la hora de expropiar bienes por deudas se buscaran primero bueyes y vacas; si no hubiera, en cerdos; posteriormente en ovejas; y por último, si el deudor no tenía ganado, en sus esclavos; por detrás sólo se situaban los bienes raíces. ${ }^{23}$

20 STELLA, Alessandro (1996), "Herrado en el rostro con una S y un clavo: I'homme-animal dans I'Espagne des siècles XV-XVIII", en BRESC, Henri (dir.), Figures de l'esclave au Moyen Age et dans le monde moderne, L'Harmattan, París, pp.147-163 (trad.1998, Palabras de la CEIBA, 1, pp. 22-32).

21 MORALES PADRÓN, Francisco (1974), Ordenanzas del concejo de Gran Canaria (1531), Ediciones del Cabildo Insular de Gran Canaria, Gran Canaria, pp. 103-4.

22 ESCOLANO PÉREZ, Víctor (ed.) (1632/1975), Ordenanzas de Sevilla, fol. 85v. 
No puedo concluir este recorrido sobre los estereotipos que rodean al ser esclavo sin aludir a otra imagen muy extendida y que atañe de manera exclusiva a la mujer. Me refiero a la de la esclava entendida como objeto sexual. ${ }^{24}$ Su arraigo en la mentalidad colectiva ha sido posible gracias a diversos factores, que abarcan desde la escasa atención que se ha prestado a las relaciones homosexuales amo-esclavo, hasta la invisibilidad que preside las relaciones ama-esclavo, entre otras cuestiones por las exigencias que imponía el papel de la mujer como depositaria del honor familiar y de la colectividad. Pero, sin duda, han sido los planteamientos de corte pretendidamente biológico los que más han fomentado su difusión. Efectivamente, las sociedades ibéricas de los siglos XIII-XV toleraban la cohabitación de amo-esclava, aunque oficialmente las relaciones fuera del matrimonio estuvieran prohibidas. ${ }^{25}$ En cualquier caso, la asunción de esta realidad no puede llevar implícito el consentimiento de la mujer esclava, pues aunque no haya muchos testimonios sobre el tema, no cabe duda de que estas mujeres eran forzadas en su mayoría. Sin embargo, la consideración de objeto legal les impedía defenderse por este motivo. Más aún, las relaciones sexuales sólo eran denunciadas cuando los dueños se consideraban perjudicados si las esclavas las habían mantenido -forzadas o consentidas- sin su autorización. ${ }^{26}$

\section{EL ESCLAVO, UN SER MARGINAL}

Independientemente de la legalidad y la legislación de la época, que convertía a los esclavos en objetos jurídicos, está claro que la población esclava estaba compuesta por seres humanos que seguían patrones de

23 FERNÁNDEZ GÓMEZ, Marcos (1991), Alcalá de los Gazules en las ordenanzas del marqués de Tarifa. Un Estudio de legislación local en el Antiguo Régimen, Cádiz, Título XLI, 31, p. 264

24 STELLA, Alessandro (1997), "Des esclaves pour la liberté sexuelle de leurs maîtres (Europe occidentale, XIVe-XVIII'siècles)", CLIO, Histoire, Femmes et Sociétés, n 5, pp. 191-209.

25 STELLA, Alessandro (2000), "Mezclándose carnalmente. Relaciones sociales, relaciones sexuales y mestizaje en la Andalucía occidental", en ARES, Berta y STELLA, Alessandro (dirs.), Negros, Mulatos, Zambaigos. Derroteros africanos en los mundos ibéricos, Escuela de Estudios Hispano Americanos, Sevilla, pp. 175-188.

26 Aunque posterior al marco cronológico de este estudio, resultan interesantes las consideraciones de GARRIDO GARCÍA, Carlos Javier (2018), "Las esclavas moriscas en el reino de Granada tras la rebelión de 1568-1571: cotización en el mercado y explotación laboral y sexual", eHumanista/Conversos, n 6, pp. 325-345. 
comportamientos sociales. La procedencia externa a las sociedades que los esclavizaban con frecuencia reveló comportamientos que chocaban y se prohibían. Al mismo tiempo, la propia marginación del colectivo favoreció la aparición de sincretismos, comportamientos y actividades practicados sólo por los esclavos que, a pesar de sus orígenes culturales diferenciados, compartían el estado de privación de libertad. ${ }^{27}$

Con todo, quiero precisar que aunque se hable en sentido genérico del esclavo, hace ya mucho tiempo que está ampliamente aceptada la premisa de que la población esclava no constituía una categoría social dado que las condiciones de vida privado de libertad diferían notablemente de un individuo a otro. En este sentido, es fácil comprender que no vivía igual un esclavo doméstico de un noble que el de un artesano. Y tampoco vivirían igual los esclavos en la ciudad que en el campo.

Sin embargo, la negación de la categoría social no puede conducir a la negación del grupo. Desde el punto de vista de la antropología cultural hay que aceptar la condición del esclavo como miembro de un colectivo cuyo nexo de unión es una cultura externa a la de la sociedad en la que se inserta, y de la que asimila nuevos modos que integra con los anteriores a través de un proceso de aculturación. En este sentido, en la Península Ibérica se podrían distinguir fundamentalmente dos grupos de esclavos, los moros y los negros.

No cabe duda de que los comportamientos ajenos a la sociedad cristiana son los que más recelo despertaban entre las autoridades castellanas. De ahí las disposiciones que prohibían que los esclavos se juntaran para celebraciones, que además podían degenerar en una alteración de la convivencia, con las consiguientes molestias para el resto de la población. ${ }^{28}$ Plazas y espacios abiertos eran puntos de encuentro ideales para buscar la oportunidad de mantener relaciones sexuales, juntarse con otros esclavos y celebrar fiestas. ${ }^{29}$ Resulta difícil establecer qué grado de espontaneidad tenían estas reuniones dado que incluso se llevaban instrumentos musicales.

27 Para el ámbito catalán me remito a ARMENTEROS, Iván (2008), "'Si tu non delinquiris'. Conflictividad en torno a la esclavitud en la Barcelona tardomedieval", Anuario de Estudios Medievales, $n^{\circ}$ 38/2, pp. 969-1007; para el ámbito castellano, en el que se centra este epígrafe, el tema se trata con mayor profundidad en GONZÁLEZ ARÉVALO, Raúl (en prensa), "Esclavitud y normativa ciudadana. Dinámicas sociales de integración y exclusión en las ordenanzas municipales de la Corona de Castilla (siglos XV-XVI)", en GUILLÉN, Fabienne y SALICRÚ, Roser (eds.), Être esclave. Dynamiques sociales, identités, acculturation, Casa de Velázquez, Madrid. 
Además, es probable que en los corros también se cantara en árabe o en lenguas del África subsahariana, al igual que está constatado con los negros en las colonias americanas.

Estas fiestas representaban una exclusión en dos sentidos: de una parte, como elemento marginal de la sociedad, la población esclava no participaba en igualdad de condiciones de otras manifestaciones sociales, recurriendo a una vía propia. A su vez, se trata de celebraciones en las que la población libre no tendría cabida, lo que aumentaría el interés de las autoridades concejiles por controlarlas y erradicarlas. Por otra parte, si tenemos en cuenta que la inmensa mayoría de los esclavos de la Península Ibérica habían nacido libres y habían sido esclavizados con posterioridad, es indudable que los corros y cánticos reforzaban la identidad cultural de origen, a la vez que rechazaban la aculturación en una sociedad que tampoco tenía más interés en integrarlos que en someterlos.

La necesidad de controlar el comportamiento de los esclavos llevó a las autoridades a legislar sobre su capacidad de movimiento. No se veía con buenos ojos que la población esclava deambulara a su antojo por la ciudad de día, habiendo espacios en los que estaba expresamente prohibida su presencia, como puertas de las ciudades o alhóndigas de los puertos. Pero con menor razón aún se aceptaba que deambularan de noche, cuando la oscuridad favorecía los delitos. Normalmente los esclavos debían estar ya en sus casas después de la puesta de sol, y sólo se justificaba que salieran de ellas acompañando a sus dueños. En algunas ciudades con un volumen de población esclava importante el ayuntamiento incluso legisló para que los dueños encerraran bajo llave y pusieran cadenas por la noche a sus esclavos, aunque todo parece indicar que la normativa no se cumplió..$^{30}$

28 Para muestra, Jerez de la Frontera, Zafra o Gran Canaria: CARMONA, Ma Antonia y MARTíN GUTIÉRREZ, Emilio (2010), Recopilación de las ordenanzas del Concejo de Xerez de la Frontera. Siglos XV-XVI: Estudio y edición, Publicaciones de la Universidad de Cádiz, Cádiz, p. 392; PERIÁÑEZ, Rocío (2011), Negros, mulatos y blancos: los esclavos en Extremadura durante la Edad Moderna, Diputación Provincial de Badajoz, Badajoz, p. 381; y MORALES PADRÓN, Ordenanzas del concejo de Gran Canaria, p. 106.

29 Así lo confirman las ordenanzas de Granada, Baeza y Llerena: Ordenanzas de Granada de 1552, (1672), edición facsímil, Granada, p. 289; ARGENTE DEL CASTILLO, Carmen y RODRÍGUEZ MOLINA, José (1980), "Reglamentación de la vida de una ciudad en la Edad Media: Las ordenanzas de Baeza", Cuadernos de Estudios Medievales, n VIII-IX, p. 73; PERIÁÑEZ, Negros, mulatos y blancos, p. 277-8. 
De todos los espacios públicos en los que la presencia esclava estaba vedada o condicionada los que indiscutiblemente comparecen de manera recurrente son aquellos relacionados con el vino y el juego. Efectivamente, las ordenanzas destinadas a bodegoneros, mesoneros, venteros y taberneros comparten prohibiciones del mismo tenor: servir vino a los esclavos y darles alojamiento. No es difícil suponer que la combinación de vino y juego derivaría con frecuencia en peleas. $Y$ aunque resulta complicado conocer el alcance del cumplimiento normativo, hay indicios que apuntan a que la población esclava encontró dificultades para acceder a estos establecimientos, lo que le llevó a buscar alternativas fuera de ellos, en casas de vecinos y amigos. ${ }^{31}$

Por lo tanto, se puede afirmar que para la población esclava las tabernas constituían puntos donde socializar con la población libre, que acudía a ellos igualmente a descansar, pasar la noche, beber, comer y jugar. La presencia esclava en estos establecimientos revela un proceso evidente de aculturación, en el que negros y moros asumieron costumbres de la población castellana. Los libres parecen haber compartido espacios y activida-

30 Numerosos ejemplos en Jerez de los Caballeros, Málaga, Gran Canaria, Lepe y Tenerife: PERIÁÑEZ, Negros, mulatos y blancos, p. 453; MARCHANT, Alicia (2002), Los escribanos públicos en Málaga bajo el reinado de Carlos I, Universidad de Málaga, Málaga, p. 82; MORALES PADRÓN, Ordenanzas del Concejo de Gran Canaria, p. 106; GONZÁlEZ GÓMEZ, Antonio (2001), Transcripciones del libro de las Ordenanzas Antiguas de Lepe, Ayuntamiento de Lepe, Lepe, p. 54; Acuerdos del Cabildo de Tenerife. Vol. IV (1518-1525), SERRA RAFOLS, Elías y DE LA ROSA, Leopoldo (edición y estudio) (1970), Instituto de Estudios Canarios, La Laguna, p. 128.

31 Las disposiciones se repiten a lo largo y ancho de la Corona de Castilla: Jerez de la Frontera, Antequera, Murcia, Baeza, Carmona, Zafra, Jaén, Loja, Ronda o Archidona. CARMONA y MARTíN GUTIÉRREZ, Recopilación de las ordenanzas, pp. 359-360; ALIJO, Francisco (1979), Ordenanzas de Antequera (1531), Universidad de Málaga, Málaga, p. 38; MOLINA, "Contribución al estudio de la esclavitud en Murcia", pp. 125-6; ARGENTE DEL CASTILLO y RODRÍGUEZ MOLINA, "Reglamentación de la vida", p. 71; GONZÁLEZ JIMÉNEZ, Manuel (1972), Ordenanzas del concejo de Carmona, Diputación Provincial de Sevilla, Sevilla, p. 121 ; PERIÁÑEZ), Negros, mulatos y blancos, p. 421; RODRÍGUEZ MOLINA, José (1983), "Los no privilegiados en Jaén (siglos XIV y XV)", Hispania, n 155, p. 495; RAMOS BOSSINI, Francisco (1981), Ordenanzas de Loja, Universidad de Granada, Granada, pp. 131-2 y 188; Antiguas Ordenanzas municipales de la ciudad de Ronda, RUIZ POVEDANO, José M. a (introducción y estudio) (2006), p. 213; ESPEJO, Juan Luis y MORALES, Eva (1998), Ordenanzas de Archidona 1598, Universidad de Málaga, Málaga, pp. 71-2. 
des, e incluso acogido esclavos en sus casas, facilitándoles un acceso a la comida y la bebida fuera del ámbito doméstico de los dueños y de los espacios públicos mencionados. Pero el alcoholismo entre la población esclava, calculado en torno al $15-20 \%$ de individuos de media en grandes ciudades como Sevilla, Málaga, Valencia o Barcelona, no se puede considerar una adaptación positiva dentro del proceso de aculturación de los esclavos. Además, la documentación tiene indicios sólidos de que se extendió más entre los negros que entre los moros, tal vez porque las leyes islámicas prohibían expresamente el consumo de alcohol. ${ }^{32}$

Relacionado con la bebida están los otros dos vértices del triángulo de conflictividad social: el juego y el robo. Porque algunos esclavos robaban para jugar y beber. La asociación con los estratos sociales más bajos y la relación con actividades condenadas socialmente como el juego, el robo y la bebida determinó que en última instancia se considerara al individuo privado de libertad un peligro social por sí mismo.

\section{VIDA Y OBRA DE LOS ESCLAVOS}

Con una presencia de esclavos tan sustancial no es difícil imaginar las importantes cifras económicas que se derivaban de su compraventa. Se trataba de una transacción comercial sujetas a las leyes del mercado como cualquier otro producto, determinada por la oferta y la demanda: así, había precios bajos si el mercado estaba saturado, y altos cuando había escasez; del mismo modo, había variables según el "estado de la mercancía", valiendo más los hombres jóvenes y sanos que los niños, ancianos y enfermos. Pero lo más interesante para perfilar los rasgos de esta esclavitud ibérica es conocer el trabajo desarrollado por estos hombres y mujeres esclavizados. ${ }^{33}$

El principal valor que define la esclavitud es el económico. Los beneficios derivados del tráfico de seres humanos y de su rendimiento laboral fueron

32 GONZÁlEZZ ARÉVALO, La esclavitud en Málag, p. 162; FRANCO SILVA, La esclavitud en SeviIla, p. 217; MARZAL PALACIOS, La esclavitud en Valencia, fol. 1082; y ARMENTEROS MARTíNEZ, "'Si tu non delinquiris'”, pp. 989-990.

33 Son fundamentales las reflexiones planteadas por FURIÓ, Antoni, (2000), "Esclaus i assalariats. La funció econòmica de l'esclavitud en la Península Ibèrica a la Baixa Edat Mitjana", en FERRER y MUTGÉ, Esclaus $i$ lliberts, pp. 19-38. Imprescindible asimismo la consulta de los artículos recopilados en el monográfico Treball esclau i treball assalariat a la baixa edat mitjana publicado en 2006 en la revista Recerques: Història, economia i cultura, 52-53. Las aportaciones más recientes en SALICRÚ, Roser (2010), "La explotación de la mano de obra 
la razón de ser de la institución a lo largo de los siglos. Sin embargo, estamos mejor informados sobre el comercio con esclavos -mercados, procedencias, precios- que sobre la verdadera naturaleza y el alcance real de la función económica de la esclavitud medieval. De hecho, esta escasa visibilidad ha conducido a una imagen de improductividad que tradicionalmente ha reducido al esclavo a un objeto de lujo en manos de los grupos sociales más adinerados. De hecho, esta imagen improductiva se extiende al servicio doméstico en general, a pesar de lo cual es irrefutable que la esclavitud como fenómeno era, de manera muy evidente, un fenómeno económico, pues el esclavo era un productor de trabajo y de riqueza, un bien objeto de toda clase de transacciones.

En realidad, el problema del trabajo de los esclavos en general se reduce a tener presente dos premisas fundamentales: la primera, que indiscutiblemente el esclavo formaba parte del grupo doméstico, que hay que considerar como una unidad de producción. La segunda, que las funciones del individuo esclavizado eran tantas cuantas quisiera el amo, ya fuesen productivas o no.

Por otra parte, es complicado constatar las actividades ligadas al ámbito más íntimo de la convivencia porque la documentación pocas veces se refiere a ellas. En primer lugar destacaban las ocupaciones domésticas, entendidas con amplitud de miras: todo lo relativo al interior y el exterior de la vivienda para la convivencia. Las tareas clásicas atribuidas, como ocuparse de la comida y la limpieza, ir al mercado, aprovisionar de agua, lavar la ropa, etc. Algunas de estas actividades se constatan en las ordenanzas municipales que regulaban la convivencia en las ciudades y otras localidades de menor entidad.

Así por ejemplo, se sabe que los esclavos se ocupaban de deshacerse de los desechos domésticos porque no siempre arrojaban la basura en los sitios indicados, sino que a veces, aprovechando la oscuridad de la noche, lo hacían en otros lugares, por la calle o junto a las murallas de las ciudades, con el consiguiente problema de suciedad.

esclava en el Mediterráneo cristiano bajomedieval desde el observatorio catalano-aragonés", Espacio, Tiempo y Forma, Serie III, $H^{a}$ Medieval, n² 23, pp. 167-183; y GONZÁLEZ ARÉVALO, Raúl (2013), "Ordenanzas municipales y trabajo esclavo en la Corona de Castilla (siglos $\mathrm{XV}-\mathrm{XVI})$ ", en CAVACIOCCHI, Schiavitù e servaggio, pp. 431-464. 
Por otra parte, acudir a las fuentes a por agua también podía provocar inconvenientes, en este caso desórdenes. En torno a ellas había esclavos que buscaban encuentros con mujeres, esclavas o no, con los peligros consiguientes porque se podían forzar dichos encuentros, se provocaban peleas y los propios esclavos dejaban de cumplir sus tareas. Por este motivo en muchas ciudades se terminó prohibiendo que los varones esclavizados acudieran a las fuentes públicas.

Entre las tareas relacionadas con la manipulación de alimentos estaba la elaboración y cocción del pan. Pero, además, los esclavos acudían a venderlo al mercado o por las calles. Con frecuencia las autoridades les acusan de cometer fraude, bien vendiéndolo más caro de lo que marcaban las ordenanzas, bien vendiéndolo al precio legal, pero de menor tamaño y peso. También vendían vino, lo que solía causar problemas con el exceso de alcohol, y agua.

Dentro del ámbito doméstico es complicado dilucidar la contribución del trabajo esclavo al artesanado. ${ }^{34}$ Con frecuencia los artesanos tenían el taller dentro de sus viviendas, en el piso inferior que también servía como almacén y tienda, habitando la familia en el piso superior. Se sabe con certeza que los esclavos participaban en el proceso productivo. En la industria textil, por ejemplo, se dedicaban a la limpieza y el hilado de fibras, a su teñido y secado, y a la elaboración de telas tejiendo en telares. Así, es frecuente encontrar esclavos cuyos dueños desarrollan oficios textiles, como roperos, sastres, tintoreros, tejeros y tundidores.

También destacaba el sector del cuero -borceguineros, curtidores, zapateros, guanteros-, seguido de los trabajadores del metal -cuchilleros, herreros, herradores, cerrajeros, armeros, espaderos- y de otros oficios entre los que sobresalían los relacionados con el sector alimenticio: carniceros, vendedores y tratantes de pescado, especieros, bizcocheros y molineros.

En la inmensa mayoría de los casos el reglamento interior de los gremios y cofradías artesanos prohibían que los maestros tuvieran como aprendices a esclavos, probablemente para preservar el monopolio y controlar la competencia. Como mucho, los esclavos ayudaban, pero sin tener un aprendizaje reglado y reconocido. Y desde luego, salvo excepciones, no

34 SALICRÚ, Roser (2009), "Slaves in the Professional and Family Life of Craftsmen in the Late Middle Ages", en CAVACIOCCHI, Simonetta (ed.), La famiglia nell'economia europea. Secc. XIII-XVIII, Firenze University Press, Florencia, pp. 325-342. 
alcanzaban el grado de oficiales, no digamos ya de maestros: era impensable que un esclavo pudiera tener un taller propio e independiente.

Los esclavos también participaban en la construcción, en obras públicas y privadas. Se ha constatado su presencia en atarazanas (Barcelona), catedrales (Barcelona, Tarragona, Mallorca, Sevilla, Málaga) y castillos (Játiva, Tortosa, Bellver y Almudaina de Mallorca, Palacio Real de Barcelona, Reales Alcázares de Sevilla, Alcazaba de Málaga) por todo el territorio. En Cádiz también había población esclava en la obra de la Torre de Hércules o de la Casa de la Sal, por citar sólo unos pocos ejemplos representativos. En las ciudades marítimas es frecuente encontrar varones esclavizados trabajando en el puerto, generalmente cargando y descargando las mercancías y los suministros de los navíos fondeados. Se trataba de trabajos duros, y que en otras ocasiones no quería nadie, como el de verdugo.

Por otra parte, hasta tiempos muy recientes se creía que la esclavitud medieval y moderna era casi exclusivamente urbana. De hecho, algunos autores negaban la presencia de esclavos en el campo. Sin embargo, van saliendo a la luz noticias sobre las actividades de la población esclava en el ámbito rural, donde también desarrollaban actividades domésticas. En este sentido, destaca sobre todas las demás la recogida de leña. Las ordenanzas de los núcleos rurales -Marchena, Zafra, Antequera, Lepe, Carmona, Écija, Ronda-suelen indicar dónde se puede recoger y de qué especies.

Esporádicamente se pueden encontrar algunos testimonios que acreditan labores de labranza entre el trabajo agrícola esclavo, generalmente en las propiedades rurales de los dueños, donde podían participar en la siembra y en la recolecta. Pero el trabajo de campo en los reinos hispanos medievales nunca se basó en la mano de obra esclava, al contrario de lo que sabemos de las grandes plantaciones americanas, donde la extensión y la explotación intensiva requería mucha mano de obra barata, facilitando la supervivencia del fenómeno y su justificación económica.

En definitiva, la población esclava realizaba una función económica complementaria en todos los sectores productivos, variando su importancia y su incidencia en función de factores tan dispares como las condiciones generales del mercado laboral, la oferta y la demanda de mano de obra esclava o el grado de especialización permitido a los individuos privados de libertad, cuya contribución productiva en las sociedades que los esclavizaban es de todo punto indiscutible.

Respecto a la vida en esclavitud, las posturas sobre la naturaleza del trato a la población esclava oscilan entre la benignidad que lo considera casi 
un miembro más de la familia, con una vida nada dura, y la visión sombría del ser humano tratado como un animal, sometido a malos tratos continuos. En este sentido, no cabe duda de que la convivencia permitía el desarrollo de relaciones marcadas por la familiaridad, independientemente de que fueran buenas o malas. Por otra parte, también resulta indudable que se establecían vínculos afectivos, en especial con los menores nacidos en esclavitud en una casa, como revelan muchos testamentos, en los que los dueños incluso se preocupan por el futuro de sus esclavos. Pero una relación larga en el tiempo tampoco garantizaba ni la libertad ni que no se vendieran los esclavos, de modo que el futuro pocas veces estaba asegurado. En cualquier caso, hay que partir de una premisa fundamental: a ninguna persona esclavizada le podía gustar su vida ni su estado, y en consecuencia la propia esclavización ya constituía por sí misma un maltrato a la persona, aunque la mentalidad de la época lo aceptara y la legislación lo sancionara. ${ }^{35}$

\section{Cualquiera podía tener un esclavo}

Frente a la idea extendida de que el esclavo era un objeto de lujo que sólo se podían permitir los grupos sociales más adinerados, lo cierto es que a finales de la Edad Media cualquiera que se lo pudiera permitir podía tener uno. Efectivamente, los datos muestran que los esclavos eran accesibles para toda la sociedad, aunque destacaban como compradores los sectores económicos propios de las sociedades urbanas como médicos, juristas y escribanos, pero sobre todo los relacionados con el comercio y el artesanado. Semejante preponderancia indudablemente estaba relacionada con el carácter doméstico de esta esclavitud urbana y el papel productivo que desarrollaban los esclavos. Por el contrario, resulta más llamativa la posición destacada que llegaban a tener las mujeres como propietarias de esclavos, si bien es cierto que se regían por mecanismos diferentes debido al papel y la posición que ocupaban en la sociedad, lo que confería mayor libertad a las viudas y a las mujeres que estaban solas. ${ }^{36}$

35 En este punto resultan indispensables las consideraciones desarrolladas no hace mucho a partir del caso valenciano en BLUMENTHA, Enemies and Familiars.

36 Para el ámbito castellano véase GONZÁLEZ ARÉVALO, La esclavitud en Málaga, pp. 313 382 , con comparaciones respecto a Sevilla y Granada; para el marco catalano-aragonés, me remito a las consideraciones de ARMENTEROS, L'esclavitud a la Barcelona, pp. 261-321. 
Por lo que se refiere a la oligarquía ciudadana, tradicionalmente presentada como el sector comprador por excelencia, no parece haber tenido la misma importancia en todas las ciudades; el carácter cerrado del grupo ha permitido estudiar no sólo su posición respecto al resto de la sociedad, sino también el grado de penetración de la esclavitud en él, y en algunos casos concretos el resultado ha sido sorprendente por inesperado. Así por ejemplo, en Málaga sólo un tercio de los individuos identificados como pertenecientes a la oligarquía ciudadana era propietario de algún esclavo, y son raros los casos en los que superaban la decena de personas esclavizadas. Por el contrario, en las ciudades de la Andalucía atlántica, con una mayor presencia de la nobleza, había aristócratas que los poseían en abundancia. Aunque se trata de un ejemplo extremo, el duque de Medina Sidonia en 1492 era propietario de noventa y seis esclavos, que aumentaron hasta alcanzar los doscientos cuarenta y ocho, según figura en el inventario de testamentaría de 1507.37

En Sevilla y en Granada junto con la nobleza el otro grupo de grandes compradores fue el de los eclesiásticos. Efectivamente, la Iglesia fue una importante dueña de esclavos, tanto las personas que la integraban como ella misma como persona jurídica. Así, los clérigos de las parroquias, los deanes de las catedrales, obispos, arzobispos y otros clérigos poseyeron esclavos, al igual que conventos y monasterios, en todo el suelo ibérico. La realidad de los hechos es que la Iglesia medieval, lejos de condenar la esclavitud -ya he referido el papel de San Agustín y Santo Tomás de Aquino en la justificación del hecho esclavo- la admitía sin ningún problema y no se observa en su comportamiento nada que indique un trato diferente respecto al resto de la sociedad de la época.

\section{LA QUIMERA DE LA LIBERTAD SOÑADA}

Aunque la esclavitud fuera un hecho aceptado comúnmente por las sociedades medievales, no lo es menos que la libertad estaba considerada el bien más preciado que tenía el ser humano. Así lo consagraba el código de las Siete Partidas de Alfonso X el Sabio de Castilla: "Aman et cobdician naturalmientre todas las criaturas del mundo la libertad, quanto más los homes que han entendimiento sobre todas las otras, et mayormientre aquéllos que son de noble corazón" (Partida IV, Título XXII, Ley I).

37 LADERO QUESADA, Miguel Ángel (1991), "Los esclavos de la casa ducal de Medina Sidonia", en Homenaje a Jacinto Bosch Vilà, Universidad de Granada, Granada, pp. 225-232. 
Sin embargo, la realidad es que, frente a la idea difundida que sitúa la liberación al final de la vida en esclavitud como algo natural y habitual, la mayoría de los esclavos no lograban abandonar su estado, pues el porcentaje de liberaciones era mínimo, como revelan las cifras de los estudios específicos: así, en Sevilla la documentación arroja un porcentaje del 18'5\%, en Málaga un $9 \%$ y en Barcelona un 15\% del total. ${ }^{38}$

La libertad por medios legales se podía conseguir de dos maneras: a través de una manda testamentaria o mediante una carta de ahorría, siendo preceptivo en ambos casos la conversión del esclavo al cristianismo. Pero, como decía, las cifras muestran que no era un acto que estuviera muy extendido. Además, rara vez se hacía sin contrapartida alguna. Así, en los testamentos de ordinario se disponía que el esclavo prestara un servicio durante un número variable de años antes de conseguir la plena libertad, lo que daba lugar a la aparición de la figura designada como criado semilibre.

Por su parte, las cartas de ahorría solían concederse como consecuencia del pago de un rescate, cuya cantidad generalmente era superior al precio de mercado, lo que con frecuencia dificultó la financiación; de hecho, los esclavos que podían permitírselo solían pagarlo a plazos, o tenían que presentar fiadores, lo que muestra las relaciones que tenía fuera del grupo doméstico, pero siempre dentro de los grupos solidarios con el mismo origen etno-geográfico: los negros ayudaban a los subsaharianos y los moros a otros de su raza.

Con respecto a los esclavos que se liberaban, el porcentaje entre negros y blancos estaba bastante equilibrado, aunque las mujeres aventajaban siempre a los varones. El arco de edad es inversamente proporcional al de las compraventas, esto es, predominaban los niños y los adultos mayores de treinta y cinco años. Los motivos que conducían a un dueño a conceder la libertad a un esclavo, al margen de las consideraciones de tipo económico, son variados, destacando dos: el afecto profesado y la falta de convencimiento de la licitud del fenómeno, no obstante la legalidad vigente. Con todo, también había razones más mezquinas, pues, como denunciaba el inmortal Miguel de Cervantes en la segunda parte de El Quijote (capítulo XXIV), también los había que "ahorran y dan libertad a sus negros cuando ya son viejos y no pueden servir, y echándoles de sus casas con título de

38 Así lo confirman los estudios de Alfonso Franco Silva, Raúl González Arévalo e Iván Armenteros Martínez ya citados en este trabajo. 
libres, los hacen esclavos del hambre, de quien no piensan ahorrarse si no es con la muerte".

Más allá del número de liberaciones, cabe destacar que el camino hacia la libertad no era un proceso lineal exento de problemas, pues en ocasiones el dueño se retractaba de su intención, o su entorno no respetaba su última voluntad, manteniendo en esclavitud a quienes en justicia eran libres. Al mismo tiempo, la imagen tópica que pretende que los grupos más acomodados eran más generosos a la hora de otorgar la libertad por su menor necesidad económica se viene abajo cuando descubrimos en un análisis atento que destacaron por su actividad liberadora las mujeres, seguidas de lejos por los miembros de la oligarquía ciudadana, mientras que los demás sectores se mostraron menos proclives a ahorrar -término técnico referido a la liberción- a sus esclavos, probablemente por la capacidad laboral que desarrollaban y el esfuerzo económico que habían sostenido para adquirirlos.

Otro medio para alcanzar la libertad era la fuga, empresa arriesgada, patrimonio en gran medida de los hombres, aunque no parece haber sido una opción generalizada ni mucho menos. ${ }^{39}$ Las razones que impulsaban a un esclavo a huir eran variadas, y hay que tener en cuenta, además de la posibilidad de malos tratos, citada de manera recurrente en la bibliografía disponible, otros factores como el tiempo transcurrido en esclavitud, el grado de integración en el entorno o la poca predisposición del dueño a conceder la libertad a través de los mecanismos legales previstos. En cualquier caso, lo que confirma es que las ansias de libertad de las personas esclavizadas eran irrefrenables, y en última instancia se manifestarían en la negación absoluta de una condición impuesta, así como de los mecanismos legales para salir de ella, y que casi nunca estaban en sus manos. Comoquiera que fuera, aquí cabe hacer una distinción muy fuerte, pues no todos los esclavos tenían las misma opciones de huir y culminar con éxito la empresa. Efectivamente, lo tenían más fácil los moros que los negros por una cuestión geopolítica: mientras el Reino de Granada se mantuvo frente a Castilla (1232-1492) fue la tierra prometida de la libertad para los esclavos moros que lograban alcanzarlo tras huir de los lugares donde les

39 En Málaga los esclavos fugados en 1487-1538 supusieron el 2'5\% del total, mientras que en Granada en todo el siglo XVI no superaron el $4^{\prime} 5 \%$. Estos datos y las conclusiones que le siguen proceden fundamentalmente de GONZÁLEZ ARÉVALO, Raúl (2014), "Ansias de libertad. Fuga y esclavos fugitivos en el Reino de Granada a fines de la Edad Media", en MARTíN CASARES, Aurelia (ed.), Esclavitudes hispánicas (siglos XV-XXI), Universidad de Granada, Granada, pp. 105-130. 
retenían esclavizados. Por el mismo motivo, la conquista del emirato nazarí y la necesidad de cruzar el Mediterráneo occidental para llegar al Magreb volvió la empresa más ardua, aunque los musulmanes de la tierra-mudéjares primero, moriscos después de la conversión forzada al cristianismo en el siglo XVI-garantizó la ayuda de los correligionarios en el intento por alcanzar el Norte de África. La nueva frontera marítima y la mayor cercanía de las costas ibérica y magrebí en el Mar de Alborán convirtió a Málaga y Almería en puntos obligados para dar el último salto hacia la libertad.

No cabe duda de que los negros lo tenían más difícil. Su propio color de piel delataba el origen esclavo. Tampoco tenían población libre en la que apoyarse, a diferencia de los moros. Por último, la lejanía de los territorios de origen, el África subsahariana, hacía prácticamente imposible que pudieran regresar a su casa, sin olvidar que muchos de ellos habían sido vendidos como esclavos a los tratantes portugueses por tribus rivales o como consecuencia de guerras intestinas, de modo que ni siquiera tenían una casa a la que regresar.

Cuando un esclavo huía se iniciaba un procedimiento para recuperarlo, con frecuencia largo, complejo y en muchas ocasiones gravoso, y sin garantía de éxito final. El dueño denunciaba su desaparición ante la justicia para conseguir una carta en la que las autoridades municipales o judiciales acreditaran que había denunciado el hecho y solicitaba la colaboración institucional para recuperarlo. Pero antes debía demostrar que el esclavo era suyo.

Una vez obtenida la fe, el dueño podía reclamar personalmente el esclavo. Sin embargo, lo más habitual parece haber sido otorgar una carta de poder para que otro realizara la búsqueda. Estos documentos recogían habitualmente nombre y edad del esclavo, color de piel, rasgos físicos concretos -tatuajes, defectos, enfermedades y minusvalías-, los hierros que pudiera llevar y la indumentaria con la que huyó, de modo que todo condujera a la identificación positiva del esclavo. Generalmente se ignora la fecha exacta de la fuga, siendo más habitual que se hable de días, semanas, meses e incluso años. Así, había auténticos profesionales dedicados a la caza y captura de esclavos fugados.

También se daban ejemplos de lo que hoy día se define como "colaboración ciudadana", en el que la población daba noticia de esclavos fugados, cuando no los capturaban y los entregaban a las autoridades personalmente. Sin duda dos eran los motivos que respaldaban esta acción: la necesidad de mantener el orden social establecido, en el que los esclavos tenían que aceptar el lugar que la sociedad que les esclavizaba les había 
otorgado y la codicia o la necesidad económica: la captura tenía un valor tasado, una recompensa.

\section{SOBREVIVIR AL ESTIGMA DE LA ESCLAVITUD: LOS LIBERTOS}

La liberación de los esclavos, por escaso que fuera su porcentaje, dio lugar a la aparición de un nuevo grupo social, los libertos, aunque su rastro es extremadamente difícil de seguir porque prácticamente desaparecen de la documentación. ${ }^{40}$

En teoría los libertos podían obrar igual que el resto de la sociedad libre. La realidad demuestra que la práctica era otra. En cualquier caso, parece claro que lo primero que hacían era conformarse una identidad nueva para comenzar su integración en la sociedad de acogida, ahora como una persona libre. Dicha integración comprendía varios aspectos, como eran aprender bien la lengua, culminar la conversión religiosa y asumir los comportamientos sociales propios de la sociedad en la que se desenvolvían.

Sin duda alguna, uno de los pilares básicos de esta integración se realizaba a través del trabajo. En este sentido, resulta indiscutible la importancia del papel del amo, de cuyas decisiones es deudora la trayectoria del futuro liberto, pues estaba condicionado por la propia visión del propietario, que decidía aprovechar o no el tiempo en esclavitud para proporcionarle una formación profesional -aunque sólo fuera en beneficio propio- que contribuiría de manera innegable a la asimilación en el nuevo marco socio-económico. En caso positivo, el antiguo dueño se convertía en un factor decisivo que ayudaba al liberto en su nuevo objetivo.

Es de suponer que estos antiguos esclavos intentarían ejercer una vez alcanzada la libertad, pero sus aspiraciones chocaban con las normativas gremiales, que con frecuencia prohibían a los libertos desempeñar los oficios que habían aprendido, o que ingresaran en sus filas. Con todo, no es menos cierto que, en los casos mejor estudiados como Barcelona, había un grupo que constituía lo que podríamos entender como un proletariado no asimilado por las corporaciones gremiales, en el que se integraban muchos

40 Ineludible en este punto el trabajo de PLAZOLLES, Fabienne (2000), "Trayectorias sociales de los libertos musulmanes y negroafricanos en la Barcelona tardomedieval", en FERRER y MUTGÉ i VIVES, Esclaus i lliberts, pp. 135-150. En el mismo volumen se puede consultar FRANCO SILVA, Alfonso (2000), "Los negros libertos en las sociedades andaluzas entre los siglos XV al $X V I^{\prime \prime}$, pp. $51-64$. 
libertos que trabajaban sin contrato, de forma que resulta imposible seguirles la pista. Por su parte, en Sevilla había negros grumetes o cargadores de barcos, mientras que otros se empleaban como albañiles, carpinteros o zapateros, e incluso como aprendices de otros oficios cuya normativa no sería tan restrictiva. Y, naturalmente, estaba el servicio doméstico, en el que se desempeñaban hombres y mujeres como criados y escuderos al servicio de las oligarquías ciudadanas. No hay demasiadas referencias sobre la soldada que ganarían, pero todo apunta a que el jornal pagado no difería en exceso del que cobrarían los trabajadores libres no cualificados.

Los escasos testamentos conservados muestran que los libertos vivían muy modestamente. Con frecuencia vestían ropas heredadas de sus antiguos amos, era raro que poseyeran una vivienda en propiedad y parece claro que muchos tuvieron que afrontar problemas económicos, hasta el punto que algunos terminaban en la cárcel por deudas. La dificultad para encontrar trabajo e ingresos abocaría a comportamientos delictivos, y en el caso de las mujeres hay testimonios que confirman que algunas ejercieron la prostitución, probablemente para sobrevivir.

Así pues, la vía de integración en las sociedades ibéricas por medio del trabajo era extremadamente difícil. En consecuencia, la supervivencia pasaba por establecer relaciones personales de otro tipo, fundando una familia o integrándose en una cofradía. Aunque son muy pocos los matrimonios constatados entre libertos, todo apunta a la endogamia. Efectivamente, los antiguos esclavos se casaban con otros que generalmente compartían la misma posición social e idéntica condición jurídica, además de un mismo origen etno-geográfico. $Y$ desde luego hubo uniones personales sin vínculo consagrado por la Iglesia. En cualquier caso, parece claro que la constitución de la familia se retrasaba a causa de la esclavitud, pues aunque el vínculo afectivo fuera previo a la liberación, por lo general los libertos se casaban una vez ahorrados. También podría ser la explicación para la baja tasa de natalidad, menor aún entre las libertas que entre las esclavas. Tal vez haya que encontrar aquí una explicación biológica: muchas de las esclavas eran ahorradas con el encargo de buscar o que se les buscara marido. Si la liberación llegaba a una edad relativamente avanzada-como de hecho ocurría habitualmente, sobre todo si no mediaba el pago de un rescate- las posibilidades para concebir se verían reducidas progresivamente. Un dato revelador en este sentido proviene de las partidas bautismales, en las que apenas encontramos hijos de libertos nacidos con posterioridad a su ahorramiento. En consecuencia, aunque escasas en número, lo más habitual es encontrar parejas de libertos sin descendencia. 
Otros, los menos, entraban en comunidades religiosas que, sin duda, aseguraban la supervivencia en libertad.

Respecto a las cofradías, parecen haber sido una vía preferente para los subsaharianos, y son ampliamente conocidas las cofradías de negros de Valencia y Barcelona en el siglo XV. ${ }^{41}$ En la Corona de Castilla destaca la cofradía de negros de Sevilla, si bien se conoce mejor su desarrollo ya en la Edad Moderna. ${ }^{42}$ Sin duda su existencia respondía a la voluntad de integrarse en una estructura contemplada por la sociedad medieval.

No es difícil imaginar que los moros libertos se dirigían a tierras del Islam -el Reino de Granada, el Magreb- para vivir en libertad, de ahí la ausencia generalizada de noticias sobre ellos. Por el contrario, el menor interés de los subsaharianos por regresar a sus lugares de origen se ha relacionado con el temor a ser reducidos a esclavitud una segunda vez, sin descartar que en esas sociedades la condición esclava, aunque hubiera sido temporal, fuera una marca indeleble. Asimismo, no se puede descartar que la posición social en las sociedades ibéricas, por difícil que resulte imaginarlo, fuera mejor que en las nativas. De cualquier forma, lo cierto es que a partir del siglo XVI muchos negros libertos emigraron desde Sevilla al Nuevo Mundo, buscando trabajo y, probablemente, un futuro mejor, lo más alejado posible del pasado esclavo y del estigma servil.

41 GUAL CAMARENA, Miguel (1955), "Una cofradía de negros libertos en el siglo XV", Estudios de la Edad Media en la Corona de Aragón, n 5, pp. 457-466; BLUMENTHAL, Debra (2005), "La Casa dels Negres: black African solidarity in late medieval Valencia", en EARLE, Thomas F. y LOWE, Kate J. P. (eds.), Black Africans in Reinassance Europe, Cambridge University Press, Cambridge, pp. 225-246; ARMENTEROS, Iván (2011), "Un precedente ibérico de las hermandades de negros", en DALLA CORTE, Gabriela, JORDÁN, Pilar, LAVIÑA, Javier, MORAGAS, Natàlia, PIQUERAS, Ricard, RUIZ-PEINADO, José Luis y TOUS, Meritxell (coords.), Sociedades diversas, sociedades en cambio. América Latina en perspectiva histórica, Universidad de Barcelona, Barcelona, pp. 143-150; ARMENTEROS, Iván (2012), "De hermandades y procesiones. La cofradía de esclavos y libertos negros de Sant Jaume de Barcelona y la asimilación de la negritud en la Europa premoderna (siglos XV-XVI)", Clio - Revista de Pesquisa Histórica, Pernambuco, n 29/2, 2012 [consulta 16 de junio de 2019: http://www.revista. ufpe.br/revistaclio/index.php/revista/article/view/234].

42 MORENO, Isidoro (1997), La antigua hermandad de los negros de Sevilla: Etnicidad, Poder y Sociedad en 600 años de Historia, Universidad de Sevilla, Sevilla. 
Los libertos que permanecían en territorio ibérico también buscaron adquirir la condición de vecinos en las ciudades en las que estaban arraigados. En Sevilla, por ejemplo, contrataban casi inmediatamente después de obtener la libertad un procurador o personero que defendería sus intereses, muy especialmente los referentes a su propia libertad cuando se cuestionaba, lo que desembocaba generalmente en un pleito, aunque no parece que hayan sido numerosos. De hecho, hay constancia de libertos apresados bajo el pretexto de que en realidad eran esclavos.

\section{Esclavitud ibérica medieval y Memoria Histórica}

En definitiva, resulta imposible negar el alcance de la presencia esclava en la España medieval, a la cabeza de Europa occidental. Su importancia se refleja en la documentación conservada, referente sobre todo a las compraventas, el trabajo esclavo y la convivencia con la sociedad libre. Este mismo patrimonio documental ha contribuido a generar una serie de imágenes como la del hombre-animal, que como todos los estereotipos esconden una realidad histórica infinitamente más compleja y rica. La complejidad al fin y al cabo que tiene toda historia con seres humanos como protagonistas.

Como en el caso de la Memoria Histórica de la Guerra Civil y la represión franquista, es responsabilidad de la sociedad rescatar y reconocer el pasado esclavista ibérico en época bajomedieval. Es tarea de los historiadores sacarlo fuera de los círculos académicos y difundirlo, al igual que se está haciendo en otras sociedades como la estadounidense, y como intenta auspiciar la UNESCO. 